\title{
Gross motor skill performance in children with and without visual impairments-Research to practice
}

\author{
Matthias O. Wagner ${ }^{\mathrm{a}, *}$, Pamela S. Haibach ${ }^{\mathrm{b}}$, Lauren J. Lieberman $^{\mathrm{b}}$ \\ ${ }^{a}$ University of Konstanz, 78457 Konstanz, Germany \\ ${ }^{\mathrm{b}}$ Department of Kinesiology, Sport Studies, and Physical Education, The College at Brockport, State University of New York, USA
}

Keywords:

Gross motor skill performance

Visual impairments

Children who are blind

Test of Gross Motor Development-Second

Edition

Whole-part-whole method

\begin{abstract}
A B S T R A C T
The aim of this study was to provide an empirical basis for teaching gross motor skills in children with visual impairments. For this purpose, gross motor skill performance of 23, 6 12 year old, boys and girls who are blind (ICD $10 \mathrm{H} 54.0$ ) and 28 sighted controls with comparable age and gender characteristics was compared on six locomotor and six object control tasks using the Test of Gross Motor Development Second Edition. Results indicate that children who are blind perform significantly $(p<.05)$ worse in all assessed locomotor and object control skills, whereby running, leaping, kicking and catching are the most affected skills, and corresponding differences are related to most running, leaping, kicking and catching component. Practical implications are provided.
\end{abstract}

\section{Introduction}

\subsection{Background and significance}

The development of fundamental motor skills during childhood is a critical component in the overall development of an individual. A child with fundamental motor skill proficiency and thus a higher motor skill competency will likely participate in more physical activities (Cantell, Crawford, \& Doyle Baker, 2008; Cawley \& Spiess, 2008; Hands, 2008; Hands \& Larkin, 2006) which provides many secondary health benefits, including both fitness and metabolic indices (Cantell et al., 2008; Sallis, Prochaska, \& Taylor, 2000; Yang, Telama, Viikari, \& Raitakari, 2006). Conversely, a child with low motor skill competence can be expected to be at increased risk for sedentary behaviors (e.g. Jarous, Lourie Gelberg, Engel Yeger, \& Bart, 2011; Magalhães, Cardoso, \& Missiuna, 2011; Smyth \& Anderson, 2000) and subsequent secondary health deficits. This evidence is particularly critical for children with visual impairments as previous research has revealed that these children are typically behind in motor skill competence (e.g. Houwen, Hartman, \& Visscher, 2008; Houwen, Visscher, Hartman, \& Lemmnik, 2007; Schneekloth, 1989) and selected, corresponding motor activities (Brambring, 2001) when compared to their sighted peers (a comprehensive review of recent research is provided in Section 1.2).

\footnotetext{
* Corresponding author at: Department of Sports Science, University of Konstanz, 10 Universitaetsstrasse, Box 30, Konstanz, BW 78457 Germany. Tel.: +497531 883473

E-mail address: matthias.wagner@uni-konstanz.de (M.O. Wagner).
} 


\subsection{Empirical evidence and desideratum}

In their comprehensive review, Houwen, Visscher, Lemmink, and Hartman (2009) identified a total of 17 studies focusing on the comparison of motor skill performances between children with and without visual impairments. Twelve studies show broad agreement that children with visual impairments perform worse on static and/or dynamic balance (Bouchard \& Tetreault, 2000; Gipsman, 1981; Häkkinen, Holopainen, Kautiainen, Sillanpää, \& Häkkinen, 2006; Johnson Kramer, Sherwood, French, \& Canabal, 1992; Leonard, 1969; Pereira, 1990; Ribadi, Rider, \& Toole, 1987; Wyver \& Livesey, 2003) as well as on fine motor skill/manual dexterity tasks (Caputo et al., 2007; Ittyerah, 2000; Reimer, Smits Engelsman, \& Siemonsma Boom, 1999; Webber, Wood, Gole, \& Brown, 2008). However, only one study (Houwen, Visscher, Lemmink, \& Hartman, 2008) was regarded as having high methodological standard and thus, will be described in detail below.

Houwen, Visscher, et al. (2008) aimed to examine motor skill performance of children with visual impairments using the Movement Assessment Battery for Children Second edition, age band 2, 3 (Henderson, Sugden, \& Barnett, 2007), which provides eight subtests on manual dexterity, aiming and catching as well as on balance. Therefore, performance of 48 children with visual impairments aged between 7 and 10 years and 48 sighted children was compared. When compared to the sighted controls, children with visual impairments showed the poorest performance on unimanual speed, eye hand coordination, catching, static balance, and dynamic balance while moving slowly. These are important information because if a child cannot maintain their balance or catch a ball, their chances for active participation in physical activity, play, and associated socialization processes (Kremer Sadlik \& Kim, 2007) dramatically decrease. Possible adaptations to balance problems were shown in a recent study by Hallemans, Ortibus, Truijen, and Meire (2011); their results revealed that children and adults with visual impairments have slower walking speed, a shorter stride length, prolonged duration of stance and double support in comparison to age related individuals with normal vision.

Reduced gross motor skill competency in children with visual impairments can partly be assumed due to a more sedentary lifestyle (e.g. Houwen, Hartman, et al., 2008) which in turn might be caused by reduced opportunities to participate in physical activities (Lieberman \& MacVicar, 2003). Often, this results from a lack of knowledge on the part of physical educators on how to appropriately modify curriculum for the specific needs of this population (Lieberman, Houston Wilson, \& Kozub, 2002). In this regard, Houwen, Visscher, et al. (2008) suggest to reduce the complexity of the task by teaching in a stable environment, allowing the learner extra instruction and practice time, and modifying the equipment by enhancing the visual cues as well as auditory input from balls, targets, and boundaries. The chances to progress with these measures are good, since children with visual impairments have been found to enjoy participating in movement activities such as baseball, football and basketball when there have been appropriate equipment, rule, and instructional modifications (Conroy, 2012; Lieberman, Robinson, \& Rollheiser, 2006; Perkins, Columna, Lieberman, \& Bailey, 2013). However, the removal of task specific constraints alone will not compensate for the fact that children with visual impairments never had or will have the chance to visually experience role models in performing gross motor skills. Therefore, it seems (even more) important to focus on how to actually teach a particular gross motor skill in this population. As a basis for developing appropriate curricula for children with visual impairments, gross motor deficits must be identified by comparing children with and without visual impairments on a variety of practically relevant tasks such as running, jumping, kicking, throwing or catching. However, comprehensive research on gross motor skill performance in this group is lacking to our knowledge.

\subsection{Study aim and hypothesis}

The aim of this study was to provide an empirical basis for teaching gross motor skills in children with visual impairments. Therefore, we basically questioned whether there are differences in gross motor skill performance between children with and without visual impairments. Considering the findings from the literature it was assumed, that children with visual impairments would show lower gross motor skill performances in comparison to their sighted peers. To identify the whole spectrum of potentially affected gross motor skills in children with visual impairments, performances of children who are blind and sighted are compared.

\section{Methods}

\subsection{Participants and recruitment}

A total of 23 boys $(N=14$; mean age $=10.00$ years; $S D=1.62$ years $)$ and girls $(N=9$; mean age $=10.44$ years; $S D=1.51$ years) diagnosed as blind on the basis of the International Statistical Classification of Diseases and Related Health Deficits 10th Revision (World Health Organisation, 2010; ICD 10, H54.0, no light perception) but no other disability, aged 612 years ( mean age $=10.17$ years; $S D=1.56$ years) were included in this cross sectional study. Participants were recruited and tested at seven summer camps for children with visual impairments across the United States (AK, AZ, CA, CT, MD, and NY).

In addition, a total of 28 sighted controls (mean age $=9.36$ years; $\mathrm{SD}=1.83$ years; boys: $N=15$; mean age $=9.40$ years; $\mathrm{SD}=2.03$ years; girls: $N=13$; mean age $=9.31$ years; $\mathrm{SD}=1.65$ years) were recruited from local schools. The study received institutional approval and each participant and their parent agreed to participate. 
Table 1

TGMD-2 modifications and cues.

\begin{tabular}{lll}
\hline Item & Equipment/space modifications & Cues used \\
\hline $\begin{array}{l}\text { Run } \\
\text { Gallop }\end{array}$ & $\begin{array}{l}\text { Sound box } 50 \text { feet away } \\
\text { Sound box 25feet away }\end{array}$ & $\begin{array}{l}\text { Run back and forth between sound sources } \\
\text { Step hop, step hop forward } \\
\text { Top }\end{array}$ \\
Leap & Fluorescent tape around bean bag to lift leg \\
Jump & & Jump forward with one foot and land on one foot \\
Slide & & Jump as far as you can with two feet \\
Striking & Beep baseball from a tee & Step side, together, step \\
Dribble & Women's basketball & Shoulder to wall, step, swing \\
Catch & Wiffle ball with bells inside & Push with fingertips waist level \\
Kick & Beeping ball on top of bean bag & Hands out, palms up, catch \\
Throw & Tennis ball, sound box & Run, step beside ball, kick with toe, follow through \\
Roll & Softball, sound box & Step with opposite foot, throw, follow through \\
\end{tabular}

Children who are blind and sighted showed comparable age (Total: $T(49)=1.70 ; p=.096$; boys: $T(27)=0.88 ; p=.388$; girls: $T(20)=1.64 ; p=.116)$ and gender characteristics $\left(\chi^{2}(1,51)=0.27 ; p=.777\right)$, wherefore a further statistical consideration of both potential confounders was disclaimed.

\subsection{Measures}

The Test of Gross Motor Development Second Edition (TGMD 2; Ulrich, 2000) was used to determine participants' gross motor skill performance in both study groups. The TGMD 2, which is validated for children with (Houwen, Hartman, Jonker, \& Visscher, 2010) and without (Ulrich, 2000) visual impairments covers six locomotor (running, galloping, hopping, leaping, jumping, and sliding) as well as six object control skills (striking, dribbling, catching, kicking, throwing, and rolling). The TGMD 2 materials were slightly modified in order to enable the children who are blind to perform all tasks; corresponding modifications and cues are listed in Table 1.

Since the standardized administration of the TGMD 2 includes a demonstration of each skill, participants who were blind were given the opportunity to receive additional instruction and/or feel the movement prior to performing a gross motor skill. The order of the testing procedure followed the TGMD 2 manual for each child. The children were assessed outdoors by professors and graduate students with expertise in the areas of adapted physical education and motor development with a focus on visual impairment. Evaluations took approximately 1520 min depending upon how much additional instruction was needed by each child.

\subsection{Data analysis}

All gross motor skill assessments were recorded with an HD flipvideo, and the video recordings were used to assess each participant's performance scores for all measures. The data of individual participants were stored anonymously, the video recordings and protocol sheets were deleted after the conclusion of data analysis; therefore, an assignment of the test results to individual participants was no longer possible. Performance was assessed based upon 35 qualitative performance criteria (process oriented components). Each criterion is evaluated as a 1, if that criterion is present, or a 0 if it is not. Each gross motor task is performed two times. Component scores are then totaled for each gross motor skill (see Table 2), and skill scores are totaled for the locomotor or object control total score, respectively.

TGMD 2 raw data are based on observations; thus, total, skill, and component scores will be presented as medians with corresponding ranges and analyzed with non parametric Mann Whitney $U$ tests (one tailed) using SPSS 21.0. To reduce the likelihood of a type I error, resulting $p$ values (a priori $\alpha=.05$ ) for total (level 1 ), skill (level 2) and component (level 3) comparisons are adjusted level wise using Bonferroni Holm method (Holm, 1979). Corresponding effects are considered as small $(\phi>.01)$, moderate $(\phi>.03)$ or large $(\phi>.05)$, respectively (see Cohen, 1988), and post hoc power $(1-\beta)$ will be reported for the discussion of non significant comparisons (Onwuegbuzie \& Leech, 2004).

Table 2

TGMD-2 scoring using the example of running.

\begin{tabular}{|c|c|c|c|c|c|c|}
\hline Skill & Performance criteria & Trial 1 & & Trial 2 & & Trial score \\
\hline \multicolumn{7}{|l|}{ Run } \\
\hline 1 & Arms in opposition to legs, elbow bent & 0 & $\underline{1}$ & 0 & $\underline{1}$ & 2 \\
\hline 2 & Brief period where both feet are off the ground & $\underline{0}$ & $\overline{1}$ & 0 & $\underline{1}$ & 1 \\
\hline 3 & Narrow foot placement landing on heel or toe & $\overline{0}$ & $\underline{1}$ & $\underline{0}$ & $\overline{1}$ & 1 \\
\hline \multirow[t]{2}{*}{4} & Nonsupport leg bent approximately $90^{\circ}$ & $\underline{0}$ & $\overline{1}$ & $\underline{0}$ & 1 & 0 \\
\hline & & Skill score & & & & 4 \\
\hline
\end{tabular}

Note: $0=$ criterion is not present; $1=$ criterion is present. 
Table 3

Comparison of locomotor total, skill and (selected) component scores between children who are blind and sighted.

\begin{tabular}{|c|c|c|c|c|c|c|c|c|c|}
\hline & \multicolumn{2}{|c|}{ Blind $(N=23)$} & \multicolumn{2}{|c|}{ Sighted $(N=28)$} & \multirow[t]{2}{*}{$z$} & \multirow[t]{2}{*}{$p$} & \multirow[t]{2}{*}{$\operatorname{adj.~} p$} & \multirow[t]{2}{*}{$\phi$} & \multirow[t]{2}{*}{$1-\beta$} \\
\hline & Median & Range & Median & Range & & & & & \\
\hline Locomotor & 21.00 & $10.00-33.00$ & 42.00 & $35.00-48.00$ & 6.10 & .000 & .025 & .85 & .83 \\
\hline Run & 2.00 & $0.00-8.00$ & 8.00 & $7.00-8.00$ & 6.37 & .000 & .004 & .89 & .64 \\
\hline Run 1 & 0.00 & $0.00-2.00$ & 2.00 & $1.00-2.00$ & 4.52 & .000 & .013 & .63 & .46 \\
\hline Run 2 & 0.00 & $0.00-2.00$ & 2.00 & $2.00-2.00$ & 4.77 & .000 & .006 & .67 & .40 \\
\hline Run 3 & 0.00 & $0.00-2.00$ & 2.00 & $2.00-2.00$ & 5.49 & .000 & .003 & .77 & .43 \\
\hline Run 4 & 0.00 & $0.00-2.00$ & 2.00 & $2.00-2.00$ & 6.49 & .000 & .004 & .91 & .65 \\
\hline Gallop & 4.00 & $0.00-8.00$ & 7.00 & $4.00-8.00$ & 5.00 & .000 & .008 & .70 & .48 \\
\hline Hop & 4.00 & $0.00-6.00$ & 8.00 & $4.00-10.00$ & 5.22 & .000 & .005 & .74 & .45 \\
\hline Leap & 0.00 & $0.00-4.00$ & 6.00 & $3.00-6.00$ & 6.18 & .000 & .006 & .87 & .65 \\
\hline Leap 1 & 0.00 & $0.00-2.00$ & 2.00 & $1.00-2.00$ & 5.63 & .000 & .004 & .80 & .51 \\
\hline Leap 2 & 0.00 & $0.00-2.00$ & 2.00 & $2.00-2.00$ & 4.78 & .000 & .013 & .68 & .52 \\
\hline Leap 3 & 0.00 & $0.00-1.00$ & 2.00 & $0.00-2.00$ & 6.01 & .000 & .006 & .85 & .64 \\
\hline Jump & 4.00 & $2.00-6.00$ & 7.50 & $3.00-8.00$ & 4.90 & .000 & .013 & .69 & .53 \\
\hline Slide & 7.00 & $0.00-8.00$ & 8.00 & $2.00-8.00$ & 2.46 & .007 & .025 & .34 & .22 \\
\hline
\end{tabular}

Notes: Run 1 = arms in opposition to legs, elbow bent; Run 2 = brief period where both feet are off the ground; Run 3 = narrow foot placement landing on heel or toe (i.e., not flat footed); Run $4=$ nonsupport leg bent approximately $90^{\circ}$ (i.e., close to buttocks); Leap $1=$ take off one foot and land on the opposite foot; Leap 2 = a period where both feet are off the ground longer than running; and Leap 3 = forward reach with the arm opposite the lead foot.

\section{Results}

Description and interpretation of results will be provided in Section 3.1 (locomotor performance) or Section 3.2 (object control performance), respectively.

\subsection{Locomotor performance}

Locomotor performances in children who are blind and sighted are listed in Table 3.

Children who are blind show a significantly lower locomotor total score in comparison to their sighted peers; the difference found, reflects a large effect.

Results of subsequent skill analysis indicate, that children who are blind perform significantly worse in running, galloping, hopping, leaping, jumping and sliding. A moderate effect can be found in the slide; all other significant differences reflect large effects whereby running and leaping are the most affected skills and thus, will be analyzed in detail below.

A detailed analysis of corresponding component scores makes it clear that,

(i) running differences are related to run component 1 (arms in opposition to legs, elbow bent), run component 2 (brief period where both feet are off the ground), run component 3 (narrow foot placement landing on heel or toe), and run component 4 (nonsupport leg bent approximately $90^{\circ}$ ); all significant differences reflect large effects.

(ii) leaping differences are related to leap component 1 (take off one foot and land on the opposite foot), leap component 2 (a period where both feet are off the ground longer than running) and leap component 3 (forward reach with the arm opposite the lead foot); all significant differences reflect large effects.

\subsection{Object control performance}

Object control performances in children who are blind and sighted are listed in Table 4.

Children who are blind show a significantly lower object control total score in comparison to their sighted peers; the difference found, reflects a large effect.

Results of subsequent skill analysis indicate, that children who are blind perform significantly worse in striking, dribbling, catching, kicking, throwing and rolling. Moderate effects can be found in dribbling and rolling; all other significant differences reflect large effects, whereby kicking and catching are the most affected skills and thus, will be analyzed in detail below.

A detailed analysis of corresponding component scores makes it clear that,

(i) kicking differences are related to kick component 1 (Rapid continuous toward the ball), kick component 2 (An elongated stride or leap immediately prior to ball contact), kick component 3 (Non kicking foot placed even with or slightly in back of the ball) and kick component 4 (Kick the ball with the instep of preferred foot (shoelaces) or toe); a moderate effect can be found in kick component 3, whereas significant differences in kick components 1, 2 and 4 reflect large effects.

(ii) Catching differences are related to catch component 2 (Arms extend while reaching for the ball as it arrives) and catch component 3 (Ball is caught by the hands only); small but non significant effects were also observed in catch component 1 (Preparation phase where hands are in front of the body and elbows are flexed; all significant differences reflect large effects. 
Table 4

Comparison of object control total, skill and (selected) component scores between children who are blind and sighted.

\begin{tabular}{|c|c|c|c|c|c|c|c|c|c|}
\hline & \multicolumn{2}{|c|}{ Blind $(N=23)$} & \multicolumn{2}{|c|}{ Sighted $(N=28)$} & \multirow[t]{2}{*}{$z$} & \multirow[t]{2}{*}{$p$} & \multirow[t]{2}{*}{$\operatorname{adj.} p$} & \multirow[t]{2}{*}{$\phi$} & \multirow[t]{2}{*}{$1-\beta$} \\
\hline & Median & Range & Median & Range & & & & & \\
\hline Object control & 20.00 & $12.00-38.00$ & 38.50 & $26.00-47.00$ & 5.69 & .000 & .050 & .80 & .86 \\
\hline Strike & 6.00 & $4.00-9.00$ & 9.00 & $5.00-10.00$ & 4.67 & .000 & .006 & .65 & .38 \\
\hline Dribble & 2.00 & $0.00-8.00$ & 6.00 & $0.00-8.00$ & 3.34 & .000 & .013 & .47 & .25 \\
\hline Catch & 2.00 & $0.00-4.00$ & 6.00 & $0.00-6.00$ & 5.45 & .000 & .004 & .76 & .47 \\
\hline Catch 1 & 2.00 & $0.00-2.00$ & 2.00 & $0.00-2.00$ & 1.07 & .143 & .013 & .15 & .04 \\
\hline Catch 2 & 0.00 & $0.00-2.00$ & 2.00 & $0.00-2.00$ & 4.77 & .000 & .006 & .67 & .40 \\
\hline Catch 3 & 0.00 & $0.00-1.00$ & 2.00 & $0.00-2.00$ & 5.94 & .000 & .004 & .83 & .56 \\
\hline Kick & 4.00 & $0.00-7.00$ & 8.00 & $7.00-8.00$ & 6.55 & .000 & .005 & .92 & .69 \\
\hline Kick 1 & 0.00 & $0.00-2.00$ & 2.00 & $1.00-2.00$ & 5.34 & .000 & .003 & .75 & .40 \\
\hline Kick 2 & 0.00 & $0.00-2.00$ & 2.00 & $2.00-2.00$ & 6.71 & .000 & .004 & .94 & .69 \\
\hline Kick 3 & 2.00 & $0.00-2.00$ & 2.00 & $2.00-2.00$ & 2.84 & .002 & .013 & .40 & .19 \\
\hline Kick 4 & 1.00 & $0.00-2.00$ & 2.00 & $2.00-2.00$ & 4.29 & .000 & .006 & .60 & .32 \\
\hline Throw & 3.00 & $0.00-8.00$ & 6.00 & $0.00-8.00$ & 3.85 & .000 & .008 & .54 & .28 \\
\hline Roll & 4.00 & $0.00-8.00$ & 6.00 & $2.00-8.00$ & 3.32 & .000 & .025 & .47 & .35 \\
\hline
\end{tabular}

Notes: Kick 1 = rapid continuous toward the ball; Kick 2 = an elongated stride or leap immediately prior to ball contact; Kick 3 = non-kicking foot placed even with or slightly in back of the ball; Kick $4=$ kick the ball with the instep of preferred foot (shoelaces) or toe; Catch $1=$ preparation phase where hands are in front of the body and elbows are flexed; Catch $2=$ arms extend while reaching for the ball as it arrives; and Catch $3=$ ball is caught by the hands only.

\section{Discussion}

\subsection{Summary and progress of knowledge}

In this study, gross motor skill performance of 23 boys and girls who are blind (ICD 10 H54.0) aged 612 years and 28 sighted controls with comparable age and gender characteristics was compared on six locomotor and six object control tasks. Results further confirm the general findings that children with visual impairments do have significant deficits in performing locomotor and object control skills (e.g. Houwen, Hartman, et al., 2008) when comparing to their sighted peers. However, the present results also provide a threefold deepening of our current knowledge. That is, that (i) children who are blind perform significantly worse in a variety of gross motor skills, whereby (ii) running, leaping, kicking and catching are the most affected skills, and (iii) corresponding differences are related to almost every movement component. This is essential information in terms of subsequent practical implications, not only for children who are blind but also for children with moderate or severe visual impairment. This break down to lower levels of visual impairment is feasible when considering the following two aspects. First, children with moderate or severe visual impairment cannot be expected to exceed the spectrum of gross motor skill deficits as shown in this study, even though the relationship between the degree of visual and motor impairment is not entirely clear, yet (in overview Houwen et al., 2009). Second, even in the case of a particular gross motor skill not affected in children with moderate or severe visual impairment, it is clear that the more one experiences that skill, the better that individual will likely perform in it (Pica, 2008; Rink, 2010; Smith \& Biddle, 2008).

\subsection{Practical implications}

Instructors must start with teaching the entire skill first through the whole part whole method. In the case of a child with residual vision, the teacher should begin by demonstrating the whole skill in the child's field of vision while explaining the motions verbally. Another option is to have a young peer demonstrate the skill while the teacher describes the movement (for the significance of peer involvement see also Ayvazoglu, Oh, \& Kozub, 2006). For example, if the motor skill is a run, the peer performs the movement and the teacher says, "swing arms forward and back, back leg bent and step with heal toe with a time when both feet are off the ground" (Lieberman \& Haibach, in press).

Once the skill is generally understood the teacher should break the skill down into its components and teach each part of the skill using either physical guidance (move the child through the motions), and/or tactile modeling (the child feels the teacher or a peer doing the motions; i.e., co active movement). For example, a child does not understand the concept of the weight transfer in the kick. The instructor can have the child feel a peer (tactile modeling) going through the motion of weight transfer several times until the skill can be executed correctly. Tactile modeling and physical guidance are two instructional techniques also used to teach children with visual impairments who may not be able to see a demonstration. Both of these techniques would be coupled with clear verbal explanation and cues such as "approach the ball, step beside the ball, kick with the instep of the foot and follow through" in case of the kick or "hands out, palms up, catch, and grip" in case of the catch. (Lieberman \& Haibach, in press; O'Connell, Lieberman, \& Petersen, 2006).

Once the child has practiced the whole skill and then refined it by executing each part, then they can put the parts together to perform the whole skill. This can also be accompanied by the cues for each step.

Finally, it is important to keep in mind that children with visual impairments can perform gross motor skills as well as their peers with sight (Blessing, McCrimmon, Stovall, \& Williford, 1993; Singh \& Singh, 1993), but they just need to be given the opportunity and time (Lieberman \& Haibach, in press; Lieberman, Ponchillia, \& Ponchillia, 2013). 


\subsection{Limitations and future perspectives}

Within this study, almost all significant differences (total, skill and component scores) in gross motor skill performance between children with (blind) and without (sighted) visual impairments reflected large effects $(\phi \geq .50)^{1}$ which underlines the clinical relevance of the findings; this even more so when considering, that this data was collected at summer camps for children with visual impairments and that many of the children assessed were at camps focusing upon athletics. Although not every child was athletic, their perceived motor competence may be higher and, therefore, they would likely perform significantly better than a child who does not attend sports camps (Shapiro, Moffett, Lieberman, \& Dummer, 2005). For this reason, it is likely that the significance found in this study would be even greater for the general population of children with visual impairments. Therefore, a replication of the findings is one central task for future research, this even more so when considering that the present study was more or less underpowered, which for example is one rival explanation of the statistically non significant findings in catch component 1 . However, the realization of an appropriate sample size seems challenging due to the low incidence and geographic dispersion of this population. Subsequent analysis should also focus upon the effects of age, gender, and level of visual impairments on gross motor skill performance in children with visual impairments as there is insufficient research in this area (Houwen et al., 2009).

\section{Conclusion}

Developing fundamental motor skills during childhood is an important component of motor skill competence which can have lifelong effects upon physical activity participation, fitness levels, and overall health and well being. Results of the present study make it clear that children who are blind are behind their sighted peers in the development of locomotor and object control skills such as running, leaping, kicking and catching. An analysis of the underlying process oriented components enabled a detailed understanding of the specific areas of weakness for the identified gross motor skills. These results provide benchmarks for an appropriate curriculum to be designed for children with visual impairments in general in the effort to decrease the motor skill gap.

\section{Conflict of interest}

The authors declare that there is no actual or potential conflict of interest.

\section{Acknowledgements}

The authors would like to thank the American Printing House for the Blind and the Fetzer Institute for their financial support for this research project.

\section{References}

Ayvazoglu, N. R., Oh, H.-K., \& Kozub, E. M. (2006). Explaining physical activity in children with visual impairments: A family systems approach. Exceptional Children, 72, 235-248.

Blessing, D. L., McCrimmon, D., Stovall, J., \& Williford, H. N. (1993). The effects of regular exercise programs for visually impaired and sighted school children. Journal of Visual Impairment E Blindness, 87(2), 50-52.

Bouchard, D., \& Tetreault, S. (2000). The motor development of sighted children and children with moderate low vision aged 8-13. Journal of Visual Impairment E Blindness, 94, 564-573.

Brambring, M. (2001). Motor activity in children who are blind or partially sighted. Visual Impairment Research, 3, 41-51.

Cantell, M., Crawford, S., \& Doyle-Baker, P. K. (2008). Physical fitness and health indices in children, adolescents and adults with high or low motor competence. Human Movement Science, 27(2), 344-362.

Caputo, R., Tinelli, E., Bancale, A., Campa, L., Frosini, R., Guzzetta, A., et al. (2007). Motor coordination in children with congenital strabismus: Effects of late surgery. European Journal of Paediatric Neurology, 11, 285-329.

Cawley, J. C., \& Spiess, C. K. (2008). Obesity and skill attainment in early childhood. Economics and Human Biology, 6, $388-397$.

Cohen, J. (1988). Statistical power analysis for the behavioral sciences (2nd ed.). Hillsdale: Lawrence Erlbaum Associates.

Conroy, P. (2012). Supporting students with visual impairments in physical education. Insight: Research and Practice in Visual Impairment and Blindness, 5(1), 3-10.

Gipsman, S. E. (1981). Effect of visual condition on use of proprioceptive cues in performing a balance task. Journal of Visual Impairment E Blindness, 75, 50-54.

Häkkinen, A., Holopainen, E., Kautiainen, H., Sillanpää, F., \& Häkkinen, K. (2006). Neuromuscular function and balance of prepubertal and pubertal blind and sighted boys. Acta Paediatrica, 95, 1277-1283.

Hallemans, A., Ortibus, E., Truijen, S., \& Meire, F. (2011). Development of independent locomotion in children with a severe visual impairment. Research in Developmental Disabilities, 32(6), 2069-2074.

Hands, B. (2008). Changes in motor skill and fitness measures among children with high and low motor competence: A five-year longitudinal study. Journal of Science and Medicine in Sport, 11(2), 155-162.

Hands, B., \& Larkin, D. (2006). Physical fitness differences in children with and without motor learning difficulties. European Journal of Special Needs Education, 21(4), 447-456.

Henderson, S. E., Sugden, D. A., \& Barnett, A. L. (2007). Movement Assessment Battery for Children - Second edition (Movement ABC-2). London: Harcourt Assessment. Holm, S. (1979). A simple sequentially rejective multiple test procedure. Scandinavian Journal of Statistics, 6(2), 65-70.

\footnotetext{
${ }^{1}$ It is possible that the comparatively low differentiation between children with and without visual impairments for the locomotor skill, sliding, may be due to the fact that children were able to achieve a high score on the slide without a flight phase even though there typically is a flight phase in proficient sliding.
} 
Houwen, S., Hartman, E., Jonker, L., \& Visscher, C. (2010). Reliability and validity of the TGMD-2 in primary-school-age children with visual impairments. Adapted Physical Activity Quarterly, 27, 143-159.

Houwen, S., Hartman, E., \& Visscher, C. (2008). Physical activity and motor skills in children with and without visual impairments. Medicine E Science in Sports E Exercise, 41(1), 103-109.

Houwen, S., Visscher, C., Hartman, E., \& Lemmink, K. A. P. M. (2007). Gross motor skills and sports participation of children with visual impairments. Research Quarterly for Exercise and Sport, 78, 16-23.

Houwen, S., Visscher, C., Lemmink, K. A. P. M. , \& Hartman, E. (2008). Motor skill performance of school-age children with visual impairments. Developmental Medicine and Child Neurology, 50,139-145.

Houwen, S., Visscher, C., Lemmink, K. A. P. M. , \& Hartman, E. (2009). Motor skill performance of children and adolescents with visual impairments: A review. Exceptional Children, 75, 464-492.

Ittyerah, M. (2000). Hand skill and hand preference in blind and sighted children. Laterality, 5, 221-235.

Jarous, T., Lourie-Gelberg. Y., Engel-Yeger, B., \& Bart, O. (2011). Participation patterns of school-aged children with and without DCD. Research in Developmental Disabilities, 32, 1323-1331.

Johnson-Kramer, C., Sherwood, D., French, R., \& Ganahal, M. Y. (1992). Performance and learning of a dynamic balance task by visually impaired children. Clinical Kinesiology, Winter, 3-6.

Kremer-Sadlik, L., \& Kim, J. (2007). Lessons from sports: Children's socialization to values through family interaction during sports activities. Discourse E’ Society, 18(1), 35-52.

Leonard, J. A. (1969). Static and mobile balancing performance of blind adolescent grammar school children. New Outlook, 63, 65-72.

Lieberman, L. J., \& Haibach, P. (in press). Motor development curriculum for children with visual impairments or deafblindness. Louisville, KY: American Printing House for the Blind

Lieberman, L. J., Houston-Wilson, C., \& Kozub, F. M. (2002). Perceived barriers to including students with visual impairments in general physical education. Adapted Physical Activity Ouarterly, 19(3), 364-377.

Lieberman, L. J., \& MacVicar, J. M. (2003). Play and recreational habits of youths who are deaf-blind. Journal of Visual Impairment E' Blindness, 97(12), 755-768.

Lieberman, L., Ponchillia, P. E., \& Ponchillia, S. V. (2013). Physical education and sports for people with visual impairments and deafblindness: Foundations of instruction. New York: AFB Press.

Lieberman, L. J., Robinson, B., \& Rollheiser, H. (2006). Youth with visual impairments: Experiences in general physical education. RE: View: Rehabilitation and Education for Blindness and Visual Impairment, 38, 35-47.

Magalhães, L. C., Cardoso, A. A., \& Missiuna, C. (2011). Activities and participation in children with developmental coordination disorder: A systematic review. Research in Developmental Disabilities, 32, 1309-1316.

O'Connell, M., Lieberman, L. J., \& Perersen, S. (2006). The use of tactile modeling and physical guidance as instructional strategies in physical activity for children who are blind. Journal of Visual Impairment \& Blindness, 100, 471-477.

Onwuegbuzie, A. J., \& Leech, N. L. (2004). Post hoc power: A concept whose time has come. Understanding Statistics, 3(4), 201-230.

Pereira, L. M. (1990). Spatial concepts and balance performance: Motor learning in blind and visually impaired children. Journal of Visual Impairment $\mathcal{E}$ Blindness, $84,109-111$.

Perkins, K., Columna, L., Lieberman, L. J., \& Bailey, J. (2013). Parental perceptions toward physical activity for their children with visual impairments and blindness. Journal of Visual Impairments and Blindness, 107, 131-142.

Pica, R. (2008). Physical education for young children: Movement abc's for the little ones (1st ed.). Champaign, IL: Human Kinetics.

Reimer, A. M., Smits-Engelsnian, B. C. M., \& Siemonsma-Boom, M. (1999). Development of an instrument to measure manual dexterity in children with visua impairments aged 6-12. Journal of Visual Impairment E Blindness, 93, 643-658.

Ribadi, H., Rider, R. A., \& Toole, T. (1987). Comparison of static and dynamic balance in congenitally blind, sighted, and sighted blindfolded adolescents. Adapted Physical Activity Quarterly, 4, 220-225.

Rink, J. (2010). Teaching physical education for learning (6th ed.). New York, NY: Mcgraw-Hill

Sallis, J. F., Prochaska, J. J., \& Taylor, W. C. (2000). A review of correlates of physical activity of children and adolescents. Medicine and Science in Sports and Exercise 32, 963-975.

Shapiro, D. R., Moffett, A. Lieberman, L., \& Dummer, G. M. (2005). Perceived competence of children with visual impairments. Journal of Visual Impairment E Blindness, 99(1), 15-25.

Schneekloth, L. H. (1989). Play environments for visually impaired children. Journal of Visual Impairment E Blindness, 83, 196-201.

Singh, R., \& Singh, H. J. (1993). Anthropometric and physiological profiles of active blind Malaysian males. Journal of Sports Medicine and Physical Fitness, 33, $378-$ 382.

Smith, A. L., \& Biddle, S. J. H. (2008). Youth physical activity and sedentary behavior: Changes and solutions (1st ed.). Champaign, IL: Human Kinetics.

Smyth, M. M., \& Anderson, H. I. (2000). Coping with clumsiness in the school playground: Social and physical play in children with coordination impairments. British Journal of Developmental Psychology, 18, 389-413.

Ulrich, D. (2000). Test of gross motor development (2nd ed.). Austin, TX: Pro-Ed.

Webber, A. L., Wood, J. M., Gole, C. A., \& Brown, B. (2008). The effect of amblyopia on fine motor skills in children. Investigative Ophthalmology \&' Visual Science, 49, 594-603.

World Health Organisation. (2010). ICD-10 classifications of mental and behavioural disorder: Clinical descriptions and diagnostic guidelines. Geneva: World Health Organisation.

Wyver, S. R., \& Livesey, D. J. (2003). Kinaesthecic sensitivity and motor skills of school-aged children with a congenital visual impairment. British Journal of Visual Impairment, 21, 25-31.

Yang, X., Telama, R., Viikari, J., \& Raitakari, O. T. (2006). Risk of obesity in relation to physical activity tracking from youth to adulthood. Medicine and Science in Sports and Exercise, 38(5), 919-925. 